\title{
Class A drug abuse: an ophthalmologist's problem?
}

AY Firth

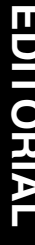

\section{Eye (2005) 19, 609-610. doi:10.1038/sj.eye.6701624}

The 2002/2003 British Crime Survey ${ }^{1}$ reported that $3 \%$ of all $16-59$ years olds (equating to around 1 million people) had used a class A drug in the last year. Use of a class A drug in the 16-24-years-old age group (8\%) has remained similar since 1996. Use of cocaine and crack cocaine are on the increase. For the first time since 1996, the use of ecstasy has decreased. Poly drug use is not uncommon. During the year 2000/2001, 118500 patients were in treatment with drug misuse agencies and general practitioners. ${ }^{2}$ Ocular sequelae from illicit drug use are varied, affecting visual acuity, visual perception, ocular posture or motility, the globe itself or its adnexa. ${ }^{3}$ Substantiated studies are not available to allow us to quantify the problem, and many of the reports are of single cases or small case series. However, an awareness of the possible problems that may arise from the use of class A drugs may alert the clinician to this as the aetiology of a condition presenting to them.

Cocaine and crack cocaine probably have the highest number of ocular problems reported from their use. Its sympathomimetic effect has led to acute angle-closure glaucoma ${ }^{4}$ and its vasoactive properties to spasms of vessels or haemorrhages. These may be retinal or in the brain stem, leading to visual loss, ${ }^{5}$ which can be transient, ${ }^{6}$ or ocular motility problems. ${ }^{7}$ Its use may also lead to cerebral vasculitis. ${ }^{8}$ It is the intense vasoconstriction combined with anaesthesia from the intranasal use of cocaine that leads to mucoperichondrial ischaemia and loss of the nasal septum. This may extend to the bony walls of the orbit. Nasolacrimal duct obstruction, orbital cellulitis, and optic neuropathy can result. ${ }^{9}$ Motility problems may not necessarily be vascular. Cocaine is known to unmask or exacerbate myasthenia gravis, possibly due to it blocking the sodium channels and slowing presynaptic neuronal transmission. ${ }^{10}$

We may be familiar with the use of cocaine as an anaesthetic agent. Decreased corneal sensitivity, the direct toxic effect of the smoke, neurotrophic changes, or vigorous eye rubbing have all been suggested as leading to corneal problems in crack cocaine users, which may include corneal ulcers, superficial punctate keratitis, and corneal epithelial defects. ${ }^{11}$ Cocaine powder may be introduced into the eye in error by contact lens wearers. ${ }^{12}$

Previously in Eye, ${ }^{13}$ I reported the onset of esotropia following heroin withdrawal and this has since been reported by others. ${ }^{14,15} \mathrm{~A}$ change in the angle of deviation in the eso direction at distance, not due to sixth nerve palsy or divergence palsy, has been found to occur following a compressed opiate detoxification regime resulting in a distance esotopia in some patients. ${ }^{16}$ This may then presumably decompensate to a constant deviation. Kowal et al ${ }^{14}$ reported that diplopia was more common following rapid detoxification and so as these programmes gain popularity more patients may present. Diplopia may also result from internuclear ophthalmoplegia following heroin use, and its resolution on use of naltrexone (an opiate blocker) is suggestive that this occurs due to an active mechanism. ${ }^{17}$

Sight-threatening conditions can occur in heroin users. Toxic amblyopia may result from using quinine either as a cutting agent ${ }^{18}$ to make the heroin taste bitter and thus of better quality, or to help the muscle cramps in self-detoxification attempts. ${ }^{19}$ Metastatic endophthalmitis from the fungus Candida albicans, transmitted from lemon juice used to prepare the heroin for injection ${ }^{20}$ or Aspergillus, an air-borne fungus, have been reported. ${ }^{21}$

Among the hallucinogenics fewer problems have been reported. While sun gazing under lysergic acid diethylamide (LSD) may lead to
Academic Unit of Ophthalmology and Orthoptics University of Sheffield UK

Correspondence: AY Firth Tel: + 441142712713 Fax: + 441142766381 E-mail: a.firth@ sheffield.ac.uk 
solar retinopathy ${ }^{22}$ and magic mushrooms to closing in of nearby space, ${ }^{23}$ it is perceptual changes that cause the main problems. Palinopsia, trailing phenomena (discontinuous stationary images that trail behind a moving object), hallucinogenic persisting perception disorder (either in the form of flash-backs or longer-lasting alterations in perception) may occur years after use and even after a single episode of LSD use. ${ }^{24-26}$ Visual perception disorder (hundreds of dots moving over whole visual field), palinopsia, and flashbacks have also been reported following use of methylenedioxymethamphetamine (MDMA), commonly known as ecstasy. ${ }^{27-29}$ Retinal haemorrhage following ecstasy use, possibly due to a sudden rise in blood pressure, has been reported in a single case. ${ }^{30}$ However, a case of bilateral sixth nerve palsy was attributed to either mild cerebral oedema or interaction of MDMA with the seratonin metabolism in the sixth nerve. ${ }^{31}$

Thus, it is apparent that a variety of ocular complaints may present to an eye casualty unit or clinic that are the result of the use of class A drugs. Clinicians need to be aware of the ocular problems that may be related to drug use so that pertinent questions may be asked regarding the cause.

\section{References}

1 Condon J, Smith N. Prevalence of Drug Use: Key Findings from the 2002/2003 British Crime Survey. Home Office Findings 229. Home Office: London, 2003.

2 Department of Health. Statistical Bulletin. Statistics from the Regional Drug Misuse Databases on Drug Misusers in Treatment in England, 2000/01. Department of Health, Statistical Bulletin: London, 2001

3 Firth AY. Ocular sequelae from the illicit use of class A drugs. Br Orthop J 2004; 61, in press.

4 Mitchell JD, Schwartz AL. Acute angle-closure glaucoma associated with intranasal cocaine abuse. Am J Ophthalmol 1996; 122: 425-426.

5 Michaelides M, Larkin G. Cocaine-associated central retinal artery occlusion in a young man. Eye 2002; 16: 790-792.

6 Libman RB, Masters SR, de Paola A, Mohr JP. Transient monocular blindness associated with cocaine abuse. Neurology 1993; 43: 228-229.

7 Nemeth G, McHenry JG, Zeiter JH, Madion P, Corder DM, O'Grady JM et al. Oculomotor abnormalities secondary to crack cocaine. Ophthalmology 1993; 100 (suppl): 632.

8 Krendel DA, Ditter SM, Frankel MR, Ross WK. Biopsy proven cerebral vasculitis associated with cocaine abuse. Neurology 1990; 40: 1092-1094.

9 Alexandrakis G, Tse DT, Roas RH, Johnson TE. Nasolacrimal duct obstruction and orbital cellulitis associated with chronic intranasal cocaine abuse. Arch Ophthalmol 1999; 117: 1617-1622.
10 Valmaggia C, Gottlob I. Cocaine abuse, generalized myasthenia, complete external ophthalmoplegia, and pseudotonic pupil. Strabismus 2001; 9: 9-12.

11 Sachs R, Zagelbaum BM, Hersch PS. Corneal complications associated with the use of crack cocaine. Ophthalmology 1993; 100: 187-191.

12 Parmar DN, Robinson F, Hunter PA. Microbial keratitis following cocaine abuse in a soft contact lens wearer. Eye 1999; 13: 264-265.

13 Firth AY. Heroin withdrawal as a possible cause of acute concomitant esotropia in adults. Eye 2001; 15: 189-192.

14 Kowal L, Mee J, Nadkarni S, Kozminsky M, Kalff S. Acute esotropia in heroin withdrawal. In: de Faber J-T (ed.) Progress in Strabismology, Proceedings of the 10th International Strabismological Association, Sydney, Australia, April 2002 Swets \& Zeitlinger: Lisse, 2003, pp. 305-306.

15 Sutter FKP, Landau K. Heroin and strabismus. Swiss Med Weekly 2003; 133: 293-294.

16 Firth AY, Pulling S, Carr MP, Beaini AY. Orthoptic status before and immediately after heroin detoxification. $\mathrm{Br} J$ Ophthalmol 2004; 88: 1186-1190.

17 Rizzo M, Corbett J. Bilateral internuclear ophthalmoplegia reversed by naloxone. Arch Neurol 1983; 40: 242-243.

18 Brust JCM, Richter RW. Quinine amblyopia related to heroin addiction. Ann of Inter Med 1971; 74: 84-86.

19 Feeney GFX, Lee GA, O'Connor PA. Quinine-induced blindness during attempted heroin withdrawal. Med J Aust 1999; 170: 449.

20 Martinez-Vazquez C, Fernandez-Ulloa J, Borden J. Candida albicans endophthalmitis in brown heroin addicts: response to early vitrectomy preceded and followed by antifungal therapy. Clin Infect Dis 1998; 27: 1130-1133.

21 Sugar HS, Mandell GH, Shalev J. Metastatic endophthalmitis associated with injection of addictive drugs. Am J Ophthalmol 1971; 71: 1055-1058.

22 Schatz H, Mendelblatt F. Solar retinopathy from sun-gazing under the influence of LSD. Br J Ophthalmol 1973; 57: 270-273.

23 Fischer R, Hill R, Thatcher K, Sceib J. Psilocybin-induced contraction of nearby visual space. Agents Actions 1970; 1: 190-197.

24 Asher H. 'Trailing' phenomenon - a long-lasting LSD side effect. Am J Psychiatry 1971; 127: 1233-1234.

25 Horowitz MJ. Flashbacks: recurrent intrusive images after the use of LSD. Am J Psychiatry 1969; 126: 565-569.

26 Woody GE. Visual disturbances experienced by hallucinogenic drug abusers while driving. Am J Psychiatry 1970; 127: 683-686.

27 Passie T, Schneider U, Emrich HM. Persisting continuous visual perception disorder in a chronic MDMA ('ecstasy') user. Aust NZ J Psychiatry 2002; 36: 266-267.

28 McGuire PK, Cope H, Fahy TA. Diversity of psychopathology associated with the use of 3,4methylenedioxymethamphetamine ('Ecstasy'). Br J Psychiatry 1994; 165: 391-395.

29 Creighton FJ, Black DL, Hyde CE. 'Ecstasy' psychosis and flashbacks. Br J Psychiatry 1991; 159: 713-715.

30 Jacks AS, Hykin PG. Retinal haemorrhage caused by 'ecstasy'. Br J Ophthalmol 1998; 82: 842-843.

31 Schroeder B, Brieden S. Bilateral sixth nerve palsy associated with MDMA ('ecstasy') abuse. Am J Ophthalmol 2000; 129: 408-409. 